\title{
Milliliters Per Millimeter of Mercury
}

National Cancer Institute

\section{Source}

National Cancer Institute. Milliliters Per Millimeter of Mercury. NCI Thesaurus. Code C106542.

A unit equal to the volume in milliliters per one millimeter rise of mercury in a barometer at the Earth's surface. 